\title{
Bahia e vaqueiros: um débito
}

\begin{abstract}
Resumo: Foi a partir da criação extensiva de gado que se fez a primeira e determinante fixação do homem nos sertões da Bahia e se estabeleceu o seu território enquanto Estado. Este fenômeno social, que sobreviveu às minas e ao açúcar, conhecido como "civilização dos currais" e, ou "civilização do couros", é o mais significativo e irradiador movimento sociocultural, responsável pela criação de um patrimônio cultural, ainda não reconhecido, e que alcança não só o Estado da Bahia, mas o Nordeste e outras regiões do Brasil. O protagonista e responsável por todo este fenômeno é o vaqueiro - um símbolo nacional - criador de um acervo cultural que abrange desde um falar, em sua rica tradição oral, toda uma variedade de bens materiais ainda sem o devido registro, salvaguarda e reconhecimento do seu significado simbólico. A Bahia tem este débito para com os vaqueiros e precisa saldá-lo reconhecendo o patrimônio cultural por eles eregido, criando equipamentos capazes de realizar o resgate, e conferir para o Estado o devido pertencimento dessa outra Bahia, que Salvador sempre desprezou e teima em não reconhecer, não obstante a riqueza que tal diversidade abriga.
\end{abstract}

Palavras-chave: Vaqueiros - Bahia. Cultura. Herança.

Com os vaqueiros saindo do Castelo da Torre em Tatuapara e convergindo para os Campos do Jacuípe e das Itapororocas, tem início o nascimento de Feira de Santana, do Estado da Bahia e do Nordeste do Brasil - a conquista do território, civilização vaqueira e patrimônio cultural.
Washington Queiroz Poeta, professor e Membro do Conselho Estadual de Cultura do Estado da bahia wsq2@hotmail.com

Foi preciso que surgisse o vaqueiro para garantir a aventura da penetração horizonte a dentro. Trazia o vaqueiro a volúpia do sol nos olhos devoradores de distâncias. E para a sua vida será necessária a largura descomunal do horizonte, que a coragem desvendara. E desenha-se o sertão através das 'rotas traçadas pelo gado'. Ao vaqueiro,

sim. Deve a vida social que [no sertão] abrolhou

intensamente. Deve a economia, que, sob a sua vista, à sua voz suja de poeira, se modelou, cresceu

e auxiliou a combalida dos canaviais [...]. Foi o vaqueiro, tangendo boiada, procurando pasto, que descobriu as terras ignoradas do sertão.

Eurico Alves Boaventura 
(1) "Este anno passado veo a esta cidade a caravela Galga de V. A. com gado vacum que he a mayor noobreza e ffartura que pode aver nestas partes e eu a mandy tornar a caregar a Cabo verde do mesmo gado". (FARIA, 1969, p. 12)
(2) Aqui consideramos que o início do povoamento da Bahia, que tem no vaqueiro a sua figura central, comecou saindo das terras de Tatuapara e se irradiou, a partir de Feira de Santana, através dos bandeirantes baianos. A despeito das consideracões de outra vertente, como nos informou Juraci Dórea, que considera que o início do povoamento está ligada ao bandeirante Peixoto Viegas.

(3) E dentro desta 'rota' a zona de Feira de Santana foi "[...] um dos seus ambientes definidos e de moldura precisa [...] conhecida, na época inicial, como campos do Jacuipe e das Itapororocas [...] que tem na Vila de São José das Itapororocas um "ponto de convergência" onde se fixa a vida pastoril até por volta de 1750 . (FARIA, 1969, p. 15)
Quando, na primeira metade dos anos quinhentos, Tomé de Souza fez chegar à província da Bahia as primeiras cabeças de gado vacum, com o objetivo de alimentar a nova cidade que surgia, por certo não imaginava que ali se estava plantando o gérmen daquele que seria o mais significativo fenômeno social para a criação do Estado da Bahia, do Nordeste e do Brasil: a civilização dos currais.

Sobre a data exata em que as primeiras levas de gado chegaram à então província para depois iniciar o palmilhar do chão sertanejo, há controvérsias entre os estudiosos. Certo é que isso já acontecia em 1550 como pode se ver em carta $^{1}$ de 18 de junho de 1551, do governador Tomé de Souza ao rei. (FARIA, 1969, p.12)

Existe a ideia de que esse gado, que tomava o litoral da então província e depois o Recôncavo, inicialmente veio para ajudar na lida dos canaviais, "no giro das almanjarras dos engenhos ou no gemer lamuriento das cantadeiras dos carros-de-bois". (FARIA, 1969, p. 12) Só depois é que veio a se iniciar o aproveitamento do gado: leite, carne e couro já que as ricas terras da costa eram para as plantações de cana-de-açucar. Mas, de parição em parição, o gado já infestava a costa da província da Bahia e precisava deixar os campos das lavouras livres. Fazia-se necessário criá-lo longe. Nessa instância, e aproveitando-se da oportunidade, os d'Ávilas, que objetivavam a exploração do ouro e do diamante em outras terras, iniciaram o processo de interiorização do gado. Como sustenta Cascudo (1965, p. 2-3):

A Casa da Torre, no seu ninho na encosta de tatuapara, nove léguas da cidade do Salvador, constituiria, com fome de terra e força irresistível, a expansão do instinto povoador, alargando os limites numa cega, diária e quase inconsciente, impulsão natural de posse dos terrenos pela pecuária. É um avanço irradiante, contínuo, geração a geração, manadas de gado conduzidas pelos guerreiros emplumados e capatazes que são os melhores mosquetes da época. [Sobre o papel das buscas das minas e do ouro no início do processo de povoamento, arremata o autor potiguar.] A idéia de 'mina' justifica a pesquisa, mas o curral de gado era a fixação. [...] O princípio da Casa da Torre fora o curral, e ela se perdeu porque desejou o ouro.

Dessa maneira começava-se a conquista do território ${ }^{2}$ do que mais tarde passaria a ser o Estado da Bahia e a região Nordeste. Como afirma o poeta feirense Eurico Alves Boaventura (1989, p. 15$)^{3}$, "[...]a marcha lenta das boiadas nos ínvios caminhos dos 
sertões traçou a rota primitiva dos destinos da Colônia que Portugal criou neste lado do Atlântico". O crescimento das boiadas nas terras da costa, o sucesso e o vulto das marchas empreendidas para o interior da província, conforme Faria (1969, p. 12), logo ganhou norma oficial pela Coroa em carta régia de $1701^{4}$.

Porém, muito antes disso, a marcha do gado já atingira a sesmaria dos Tocós - que abrangia o território onde se ergueria Feira de Santana - doada em 1609 a Antônio Guedes de Brito, um grande criador de gado da província, já naquela época. Se não era de forma intensa, como se deu a partir de 1650, em virtude das lutas com os holandeses na costa e com as tribos indígenas Aimoré, Paiaiá e Tapuia do interior, o certo é que a marcha para o sertão empreendida pelos d'Ávila anunciava de forma irreversível a tomada do sertão pelo gado. Ao Recôncavo, com o seu rico massapé, cabia quase que exclusivamente o cultivo da cana. Como diz Poppino, em seus estudos sobre o comércio de Brasil chamando a atenção para o papel desempenhado por Feira de Santana. "Em certo sentido, a história de Feira de Santana pode ser considerada como a história da pecuária na Bahia". (POPPINO, 1969, p. 54-58)

Uma parte da sesmaria dos Tocós retornou ao domínio da Coroa e foi subdivida em áreas menores e doadas a outros criadores. Numa dessas partes se encontrava a área da paróquia de São José das Itapororocas, que abrangia a área de currais e rancho de gado que mais tarde seria denominada fazenda de Santana dos Olhos d'Água. Propriedade do casal português Domingos Barbosa de Araújo e Ana Brandão, esta fazenda, após construir uma capela para devoção a Santana e a São Domingos e em virtude do seu desenvolvimento em torno do gado, deu origem a uma feira em Santana dos Olhos d'Água que mais tarde passou-se a chamar Feira de Santana.

Mas, de acordo com os estudos de Poppino, a multiplicação dos currais de gado que tinha, até por força da lei, de sair da orla da província da Bahia, teve sua primeira grande concentração comercial acontecida, transformando-se mesmo numa feira, "na parte norte do recôncavo onde havia [ainda] extensas pastagens de gado", num local chamado Capuame. É nesse percurso do desbravar o chão da Bahia, iniciado em 1550, empreendido pelos d'Ávilas, e no pontear com currais o seu território, que se deu a primeira feira de gado na Bahia, quiçá do Brasil, ainda no século XVI. O que significa dizer que, inicialmente, mesmo o gado criado nos campos de São José das Itapororocas e do Jacuípe é tangido
(4) "O gado tinha de ser criado longe, retirado, de sertão a dentro pelo menos de dez léguas arredado dos canaviais." 
em longas viagens até a feira de Capuame. E daí era levado para abastecer a capital da província da Bahia.

Mas os currais estabelecidos nos campos de São José das Itapororocas e do Jacuípe cresciam de forma avassaladora ao ponto de ainda no início dos anos oitocentos já firmar esta região como o local da maior feira da Bahia e, possivelmente, do Nordeste e do Brasil. Isso pela sua posição geográfica, inclusive não só em relação à capital mas ao Rio São Francisco e ao Nordeste e também por ser banhado por dois grandes rios, além de riachos, olhos d'água e também pelas suas fartas pastagens. Em 1819 emprestava seu nome ao povoado. Era a feira "do grande e populoso arraial de Santana dos Olhos d'Água, onde, nas terças-feiras de cada semana, se ajuntam de 3 a 4 mil pessoas". (POPPINO, 1969, p. 56)

Este movimento irradiador que levava à conquista de território, também ia criando e construindo no ferrão, facão, e no casco dos cavalos e bois, as chamadas 'estradas' para a necessária comunicação além da comunicação hidroviária. Em realidade não eram estradas e sim caminhos para a passagem das grandes boiadas que podiam chegar a trezentas cabeças. Da mesma maneira que o pouso das boiadas e o estabelecimento dos currais significaram, como aconteceu com Feira de Santana, a origem da maioria das cidades do sertão nordestino, como salienta Cascudo (1965, p. 1-7), as estradas seguiram a rota que o gado ia abrindo. Os caminhos do gado, as chamadas estradas de boiadas, como quem morou em Feira de Santana, nos bairros dos Olhos d'Água, na rua Araújo Pinho, até a década de sessenta cansou de ver, foram as origens de muitas das nossas principais estradas de hoje, a exemplo das estradas que ligam Salvador a Feira e esta a Ipirá, Mundo Novo e a Riachão do Jacuípe, Jacobina, Juazeiro, para citar apenas estas.

Desse modo, e isso não é nenhuma novidade, Feira de Santana deve sua existência às feiras de gado. A vida se dava em torno da feira de Feira de Santana, que até então acontecia dentro da vila, no entorno da capela de Santana e que, a partir de 1838, passou a ter um local definido por lei municipal, e chamado de Campo de Gado ou Campo da Gameleira. (POPPINO, 1969, p. 57)

Assim, após as incursões feitas, no sentido do ouro e das pedras preciosas, sob as ordens de Garcia d'Ávila, pressionado a procurar maiores pastos que os da sua Tatuapara, mas que resultaram na colonização do território da província da Bahia, com a fixação dos primeiros currais, os Campos das Itapororocas e do Jacuípe 
se transformaram num ponto estratégico centrípeto e centrífugo oriundo das primeiras estradas de boiada. E que, para o poeta e estudioso do tema Eurico Alves significava bem mais que isso, pois assim se refere ao assunto em seu livro Fidalgos e Vaqueiros. "Nascia ao toque das boiadas a vida da pátria [...] a música do aboio despertou o Brasil." E continua:

Recordando-se o fastígio, a opulência que a cana derramou no Recôncavo, modelando o fenômeno social que se conhece por civilização do açúcar, e o brilho momentâneo das minas, temse de evocar a civilização do pastoreio, sua contemporânea e que a ambas sobreviveu. Um dos seus ambientes definitivos e de moldura precisa foi a zona da Feira de Santana, conhecida, na época inicial como Campos do Jacuípe e das Itapororocas. (BOAVENTURA, 1989, p. 15)

Feira se Santana se afigura, portanto, na Bahia e no Brasil como um centro de irradiação dos pastos, currais e, depois, das casas de fazenda.

Até aqui falamos do desbravar das boiadas e do consequente alargamento dos horizontes do território da província da Bahia que foi encetado pela civilização dos pousos e currais, iniciado nas terras da Tatuapara e irradiado a partir de Feira de Santana. Mas quem foi a figura humana responsável por esta lenta e esplêndida marcha mugida e aboiada pelos sertões; pela civilização do couro e depois pastoreio? Quem foi este criador, o criador de uma civilização?

Este homem que pode ser considerado a maior escultura viva erigida até hoje nos sertões do Nordeste e de outras regiões do Brasil; este homem que singrou cada palmo de chão à procura de pastos bons e maiores para a criação de gado vacum que, com o rebanho se avolumando, já não podia viver beirando a orla, soube que imprescindível era, portanto, descortinar o horizonte longínquo do sertão; esta escultura humana, que ampliou a geografia da então colônia trocando o canavial pela caatinga e a roupa de algodão pela roupa de couro ${ }^{5}$, de que se vestiu da cabeça aos pés; a esta escultura - figura emblemática do sertão e nordeste brasileiros -, chamo-a: O VAQUEIRO.

Condutor do gado e pastor responsável pelos cuidados com as boiadas, o vaqueiro em sua armadura a lembrar um soldado
(5) É preciso chamar a atenção que se trata do único traje brasileiro de trabalho que tem quase a idade do país (e que só é superado pelas indumentárias à base de pinturas e penas usadas pelos nossos índios) e que ainda pode ser encontrado em uso no sertão. 
(6) Em trabalho de campo realizado em 37 municípios do sertão baiano em 1985 e 1987, pudemos observar que em muitos deles, essa realidade do vaqueiro encourado dos pés à cabeca, de certa forma, ainda existia. É existe ainda hoje em algumas reservas recônditas do território baiano. medieval, também servia como guerreiro na tarefa de ampliar os campos para a criação. À medida que se interiorizava e que se dava a mescla com indígenas, mais se fazia ver a presença de sangue indígena em seus semblantes, isso até por volta do século dezoito, até se transformar naquilo que se convencionou chamar no interior de caboclo, que, em realidade, corresponderia ao nosso mameluco, fruto da miscigenação entre brancos, negros e índios.

Os vaqueiros eram os mais mesclados entre os grupos sociais de Feira de Santana e, sob certos aspectos, constituíam o grupo mais importante. Proveniente dos habitantes sem terra do litoral, os vaqueiros primitivos incluíam brancos, mulatos e negros livres, bem como índios e mamelucos. No interior, contudo, devido à miscigenação e à conquista, o sangue índio logo passava a predominar entre os vaqueiros. Era a única posição da nova sociedade em que os índios realmente se sentiam bem. Os índios haviam sido empregados como escravos nas plantações de açúcar do Recôncavo, mas, com pouco sucesso. (POPPINO, 1969, p. 87-88)

Este homem que na figura da dinastia dos d'Ávila da Casa da Torre, iniciou a expansão pastoril saindo das areias do litoral, atravessando o massapê do Recôncavo e varando os carrascais espinhentos da caatinga, aqui não deve ser visto apenas como símbolo de intrepidez e coragem, como um guerreiro. Foi ele - o vaqueiro $^{6}$ - a força motriz da expansão pastoril. Aquele que contribuiu de forma decisiva para a criação do fenômeno socioeconômico da pecuária em toda a região Nordeste e em outras regiões do país.

Este fenômeno foi fundado em dois momentos: o primeiro, com a criação e estabelecimento dos primeiros currais, que tem início no século XVI e vai até meados do século XVIII; o segundo, quando o senhor feudal começa a erguer em pleno sertão as chamadas casas-de-fazenda, que predominam desde a segunda metade do século XVIII.

De acordo com Boaventura (1989, p. 21-24):

A cada pouso novo, a cada curral levantado, uma raiz mais funda se ia cravando na terra. [...] Na fazenda de criar, a mais forte origem da nossa civilização. E o cadinho mais adequado para a fixação da nossa gente, pela ausência de influência exótica, 
de início. Não fossem as nossas fazendas de gado, largadas na amplidão do Nordeste, no côncavo das serras além do Jacuípe e do Itapicuru, para além do Paraguaçu e do Rio de Contas, e não teríamos este produto racial a que chegamos.

Foi, então, a partir das bandeiras baianas que o território do estado da Bahia se criou e se estabeleceu. Esta "geografia dos currais" teve na fixação dos currais sua primeira instância de assentamento do homem nos sertões da Colônia. Como diria Câmara Cascudo, foi feito - o território da Bahia e do Nordeste - das impressões deixadas pelo gado; dos cascos dos cavalos dos primeiros vaqueiros, que buscavam pouso e assentamento para os rebanhos que cresciam, alcançavam o Piaú e voltavam inundando de gado o São Francisco até alcançar Minas Gerais. Nessa busca do ambiente próprio para o criatório bovino, sem rumo certo e solitário, foi o vaqueiro bandeirante que pontuou com locais de pouso, currais, primeiros arruados, aquilo que viria a ser em número bastante razoável as cidades do sertão do Nordeste.

Vê-se que em toda parte por onde rolou um aboio vespertino para o pouso, marcando o final de uma marcha, ou se acendeu a trempe para o repasto rude de uma tropa, caiu a semente de uma cidade ou vila sertaneja. A história de muita vila, de muita cidade, quando não é o eco de um salmo ou de um a ladainha [...] é a ressonância de um aboiado, de uma estrada das grandes boiadas [...] e houve cidade que nascendo de simples curral fez de um mourão deste um símbolo seu [...]. (BOAVENTURA, 1989, p. 39)

Exemplos? Além de Feira de Santana, são inumeráveis, não só na Bahia como em todo o Nordeste. Basta fazer-se a comparação da trilha do gado nesta região com a aparição das primeiras vilas. (CASCUDO, 1965, p. 1-17)

Mas durante este percurso que começa no século XVI, quando os homens da Casa da Torre empreenderam a conquista do novo chão, passa pelo século XVII, onde efetivamente esta foi concretizada, e atinge no século XVIII dos sertões do Maranhão a Bahia, se espraiando aos pastos bons do Piauí, Goiás e aos de Minas 
Gerais, fez-se necessário um sem número de criações que exigiram argúcia e maestria dos vaqueiros. Foram criados e recriados equipamentos, técnicas, procedimentos, saberes que pudessem possibilitar esse desbravar pelas caatingas, matas, agrestes, cerrados, chapadas, planaltos. Onde xiquexiques, umbuzeiros, pausde-rato, macambiras, unhas-de-gato, rasga-gibãos, mandacarus, cipós, paus-de-culé, gravatás, juntamente com outros espécimes, compunham uma flora de difícil penetração, predominantemente de vegetação arbustiva densa até a arbustiva rala, que constituía uma "[...] paisagem dura, angulosa, de ervas raquíticas e com seu caos de pedras cinzentas cravadas em desordem no chão de argila seca, rachado pelo sol e vastas regiões de areia ardente". (BASTIDE, 1975, p. 86) Enfim, uma flora e uma fauna com as armadilhas naturais e a surpresa do guerrear com as tribos indígenas que tinham suas terras invadidas e buscavam defendê-las. Só a coragem do vaqueiro se deu a transpor tais obstáculos.

Foi no mugido dos bois, no estalido dos espinhos e serrapilheira, por entre cipós e pontas de paus e envolto no lirismo mavioso e lamuriento do aboio, que nasceu Feira de Santana e o estado da Bahia. Ou melhor, a BAHIA. Não apenas a 'Baía' de Salvador, mas verdadeiramente, o estado da Bahia. E como isso se deu? Na ponta do ferrão ou "guiada" (uma espécie de lança), ou do "pau-de-ferro" como costumam chamar alguns vaqueiros, e com o vaqueiro vestindo-se de couro do coco da cabeça aos pés, para poder - e isso não é exagero - vestir de couro também Feira de Santana, a Bahia e o Estado do Sertão, que convencionou-se chamar de Estado da Bahia. E, bom que se grife, que abrange não só o sertão do estado da Bahia, como também o sertão dos outros estados do Nordeste e de outras regiões do Brasil.

Foi, portanto, em cima do cavalo arreado e assim vestido que o vaqueiro conquistou, palmo a palmo, sesmaria a sesmaria, a nova morada do gado e que se fez a fixação nos longínquos sertões. Fezse, dessa maneira, portanto, o povoamento da hoje Feira de Santana, do estado da Bahia - e aqui, repito mais uma vez, imperativo se faz não confundi-lo com a cidade de São Salvador ou Cidade da Baía - e do Nordeste e de outras regiões do Brasil.

Assim ergueram-se os currais e com eles teve origem, em virtude das poucas possibilidades do meio, o fenômeno denominado por "época do couro", "reino dos encourados", "civilização dos vaqueiros" ou "civilização coriácea" de Guimarães 
Rosa. Tal fenômeno sociocultural, considerando a sua importância histórica para vastas regiões do Brasil, ainda hoje carece de estudos sistemáticos e aprofundados.

Como lembra Boaventura (1989, p. 35), citando Caio Prado Júnior:

Não é com justiça que se relega em nossa história para o plano secundário a nossa pecuária [...] Certo que não ostenta a lustre dos feitos políticos, nem aparece na primeira ordem dos grandes acontecimentos do país. Recalcada para o íntimo dos sertões, escondem-na à vista a intensa vida do litoral, os engenhos, os canaviais, as outras lavouras. E não tem os atrativos do ouro e dos diamantes. No entanto, já sem contar o papel que representa na subsistência da colônia, bastaria à pecuária o que realizou na conquista de território para o Brasil, a fim de colocá-la entre os mais importantes capítulos de nossa história. Excluída a estreita faixa que beira o mar e que pertence à agricultura, a área imensa que constitui hoje o País divide-se, quanto aos fatores que determinam a sua ocupação, entre colheita florestal, no extremo Norte, a mineração no Centro-Sul, a pecuária, no resto. Das três, é difícil destacar uma para o primeiro lugar desta singular competição. Mas, senão a mais grandiosa e dramática, é a pecuária pelo menos a mais sugestiva para os nossos olhos de hoje $[\ldots]$.

A "civilização do couro" deu origem a um falar específico e a uma tradição oral que reúne saberes e toda uma gama de equipamentos que constituiu a base para, praticamente, toda a vida dos currais e, de certo modo, das primeiras casas-de-fazenda. O couro fora então a um só tempo a alma e corpo, - a origem do traço marcante de toda produção material do sertão. Dele - do couro - nascia uma infinidade de bens que foram imprescindiveis ao estabelecimento do homem naquelas plagas. É de posse do couro, como matéria-prima para as mais variadas atividades do campo, que o homem vaqueiro trava o seu embate com a natureza e se estabelece. Aí está também a origem de toda uma produção ergológica vaqueira. Verdadeiro patrimônio a dar conta do saber do nosso sertanejo primeiro: suas "insperiença", como diz ele até hoje, 
(7) A partir de 1985 até 1991 período em que realizamos uma pesquisa de campo sobre os vaqueiros da Bahia, em que visitamos mais de quinhentas localidades de municípios baianos, registramos, em passagem por Feira de Santana, que o gado, já àquela época, também era tangido por homens pilotando motocicletas, conforme pode ser visto em reportagem feita pelo Jornal do Brasil em 12/06/88, $1^{\circ}$. Caderno p.16. sua "ciença", que muita gente desconhece e como diz o compositor Paulinho da Viola é a "ciença da abêa".

Patrimônio erguido com suor, poeira, espinhos e sangue com vida e morte; patrimônio erguido no silêncio das sombras dos umbuzeiros; no descanso da perseguição de um "marruá alevantado"; entre uma corrida e outra; nas estórias contadas nos alpendres das casas de barro batido ou mesmo debaixo do sol mais inclemente do sertão, que sulcou na cara do vaqueiro o mesmo desenho de rachaduras que é a marca daquele chão.

Como afirmam alguns estudiosos, a exemplo de Faria (1969, p. 14) e Boaventura:

[...] era tudo tirado do boi [...] couro de arrasto para mover a terra e carregar a pedra; couro de pisar para reduzir o tabaco a rapé; couro de curtir para apurar o sal; couro de bainha para facões, facas e guicés; couro de trança para cordas, cabrestos, chicotes e arreios; couro cru para atilhos e peias; couro surrado para bruacas, mochilas, borrachas de água, alforjes e surrões; couro pregueado nas malas e baús, cadeiras, [camas] e tamboretes, nos catres usados para as doenças e partos; enfim, o couro curtido para a roupa do vaqueiro que lhe permitia percorrer o solo de carrascais e varar a vegetação espinhenta na veloz e intrépida carreira dos seus cavalos. (BOAVENTURA, 1989, p. 18)

Com o surto desenvolvimentista, que foi iniciado no primeiro governo de Getúlio e que da década de 1950 para cá se expandiu com a industrialização e as revoluções tecnológicas, a pecuária extensiva de gado, foi gradativamente desaparecendo ${ }^{7}$. Fez-se necessário produzir mais e mais em menor área de terra. O gado deixou de ser criado à solta e passou a viver limitado por cercas e em currais: aumentaram-se as zonas de pastagem e diminuíram-se as áreas de rebanhos soltos. O campo então se transformou em pastos. A Caatinga a mata e o cerrado começaram a ser dizimados. Não só para virarem carvão vegetal e pasto, e depois para o confinamento do gado, mas também para darem lugar às monoculturas que a indústria reclama.

Vias férreas e rodovias encurtam distâncias. Com isso a "civilização coriácea" vai paulatinamente desaparecendo. Os 
utensílios de couro são progressivamente substituídos pelos da indústria, o carro de boi vai sendo trocado pelo automóvel, o cavalo arreado vai cedendo espaço para as bicicleta ou motocicletas tangerem o gado, e os vaqueiros começam a desaparecer. Como nos declarou o vaqueiro Zé de Dudu, em 1985, no município de Jacobina: "Aqui, mais uns tempo não ixiste mais vaquero não. Purque eu num tenho visto mais gado, purque não ixiste mais catinga. As catinga vai alonjano e aí acaba os vaquero, né?" 8

No Brasil, a política de preservação do patrimônio sempre esteve voltada para o bem físico, plástico - aquilo que, para o regalo dos olhos, se pode ver! - sobretudo, o arquitetônico. No estado da Bahia, a então Fundação do Patrimônio Artístico e Cultural da Bahia, depois Instituto do Patrimônio Artístico e Cultural (IPAC), instituição responsável pela preservação da memória, não atuou diferente, a rigor foi criado dentro do binômio turismocultura: ou seja, a memória é uma mercadoria e deve reproduzir o capital. Tal visão impediu que, além do bem físico, outros, de significativo valor histórico-cultural, pudessem ser resgatados, registrados e incorporados ao acervo patrimonial da Bahia. Dentre estes, injustificado e injustamente, se encontra o manancial do patrimônio sertanejo que através do vaqueiro se criou chegando a Feira de Santana e daí se difundido Bahia e Brasil adentro.

Injustificadamente, até 1984, os valores culturais, o falar, técnicas e tradições do universo sertanejo, que, é bom que se diga, expressam um modus vivendi, não angariaram das políticas de preservação do patrimônio nem mesmo o pouco cuidado que o patrimônio físico, sobretudo os bens arquitetônicos do fausto período colonial em Salvador e, quando muito, no Recôncavo, obtiveram. É dentro desse âmbito que escapa o registro da rica memória do Vaqueiro e do nosso Sertão: seu falar; seus saberes, técnicas, medicina; sua moral, ética, estética; sua relação com a morte e sua vida; seus cantares, ritos, mitos, suas cosmologias e seus símbolos. Nem mesmo os bens físicos, móveis e imóveis merecem qualquer tipo de registro sistemático, inclusive arquitetônicos - as casas dos vaqueiros -, plasmados a partir da "época dos currais" e das "casas de fazenda", onde construções, tipos de cercas, equipamentos, ferramentas, vestimentas, utensílios os mais diversos e de usos variados, tendo o couro como matéria-prima para fazer-se de tudo ali e criar a vida, nada, nada disso foi considerado.
(8) Aqui, por vaqueiro, entendemos o homem que tem, ou tivera, como função precípua lidar com o gado no ambiente de vegetação de caatinga; que para tal precisa estar devidamente paramentado com as vestes de couro e equipamentos, como o ferrão, o facão, peias etc., como também com o seu cavalo devidamente arreado e protegido. Anotações de campo do autor em 1985. 
Urge, então, que passos mais largos e rápidos sejam dados no sentido da historiografia sertaneja e, por conseguinte, dos vaqueiros. O Brasil tem este débito. A Bahia tem este débito. A Feira de Santana compete, em especial, um papel preponderante. Primeiro, no sentido de reconhecer a sua origem e importância nesse processo e absorver a sua tão rica identidade, tentando recuperar o tempo perdido trabalhando para resgatar o que ainda não se perdeu de todo, mas que está, a cada dia que passa, rapidamente desaparecendo. E segundo, com isso tirar proveito e colar de fato ao seu nome, o sertão - os vaqueiros, muito além de um simples topônimo que apenas, tão só e frouxamente, adorna o seu nome: Feira de Santana - a Princesa do Sertão.

Como salienta o grande estudioso do nosso sertão, o professor José Calazans, no prefácio que escreve no primeiro volume de Histórias de Vaqueiros: vivências e mitologia. (QUEIROZ, 1987, p. 12)

\footnotetext{
Na hora crepuscular do heróico sertanejo, quando tudo indica sua crescente decadência no mundo da caatinga, quando a rês tresmalhada vai ficando muito além daquela serra que ainda azula no horizonte, é mister que o homem do litoral ouça bem o aboio do vaqueiro, referto de uma mensagem cultural e humana bem nítida.
}

Oportuno é conclamar e dizer que cabe a Bahia, e em especial a Feira de Santana, até como uma forma de não desprezar a sua origem, buscar uma linha de ação com vistas a se fazer o registro, o resgate e todo um estudo contínuo sobre a memória, o patrimônio tangível e intangível capitaneado pelos vaqueiros, bem como, e sobretudo, a sua disponibilização à formação dos estudantes e ao conhecimento e entretenimento cultural de visitantes e turistas, através de um organismo que seja uma referência nacional e internacional do acervo patrimonial erigido pela civilização vaqueira. Tal linha de ação e pesquisa deve buscar sensibilizar os órgãos de preservação da memória, já que, como salienta o poeta Eurico Alves Boaventura (1989, p. 45), trata-se de uma "[...] civilização não estudada ainda, não projetada devidamente em ensaios, que está a exigir. E até mesmo negada". E, sobremodo, por ter desempenhado o pastoreio o papel determinante para se 
adentrar as terras do sertão, seu povoamento, e nela criar toda uma vida rica em seu aspecto social e cultural que foi responsável por contribuir para com uma unidade nacional.

Ao patrimônio feirense, baiano, nordestino e nacional, nos seus 508 anos, se faz necessária a incorporação de todo o arsenal da cultura sertaneja, antes que os verdadeiros fundadores de Feira de Santana, do Estado da Bahia e do Nordeste do Brasil, no seu sentido de extensão geográfica, - o tetracentenário e derradeiro Vaqueiro, escultura viva de mais de 458 anos - definitivamente "largano os couro", debruce-se em uma cancela dos confins do Sertão e entoe um último e lamuriante aboio que se perderá numa capoeira infinita arranhando fundo e de forma irrecuperável e indelével, mais uma vez, a memória nacional.

\title{
Bahia and cattle raisers: a debt
}

\begin{abstract}
It was from extensive cattle raising that the first fixed human settlement in the interior of Bahia occurred and this led to the establishment of the territory as a State. Known as "cattle pens civilization" or "leather civilization", this social phenomenon has survived mining and sugar cultivation and is the most significant socio-cultural movement of the State. It is responsible for creating a cultural heritage to be recognized that reaches beyond Bahia to the Northeast and other regions of Brazil. The cattle raisers are the protagonists and people responsible for the creating a cultural heritage that ranges from a specific way to speak in its rich oral tradition to a variety of material goods without documentation, protection and recognition of its symbolic meaning. Bahia has this debt to the "vaqueiros" and it is important to pay off this debt recognizing the cultural heritage they have constructed. Mechanisms to preserve and rescue this culture are required which the Capital has always despised are required to protect its richness and diversity.

Key Words: Cattle raisers. Sertao. Cattle pens. Leather. Culture. Heritage.
\end{abstract}




\section{REFERÊNCIAS}

BASTIDE, Roger. Brasil: terra de contrastes. 6. ed. São Paulo: Difel, 1975.

BOAVENTURA, Eurico Alves. Fidalgos e vaqueiros. Salvador: Centro Editorial e Didático da UFBA, 1989.

CASCUDO, Luís da Câmara. Tradições populares da pecuária nordestina. Rio de Janeiro: Ministério da Agricultura / Serviço Informação Agrícola, 1965. (Documentário da Vida Rural; 9).

A vaquejada nordestina e sua origem. Recife: Instituto Joaquim Nabuco de Pesquisas Sociais, 1969.

FARIA, Oswaldo Lamartine de. Encouramento e arreios do vaqueiro do Seridó. Natal: Fundação José Augusto, 1969.

POPPINO, Rollie E. Feira de Santana. Salvador: Itapuã, 1969.

QUEIROZ, Washington. Histórias de vaqueiros: vivências e mitologia. Salvador: Instituto do Patrimônio Artístico e Cultural da Bahia, 1987. v. 1 Bahia, 1988. v. 2 Salvador: Instituto do Patrimônio Artístico e Cultural da

QUEIROZ, Washington. Projeto histórias de vaqueiros: vivências e mitologia. Salvador: Instituto do Patrimônio Artístico e Cultural da Bahia, 1988.

Sertão: onde o sol se veste de couro para se pôr. Revista da Bahia, Salvador, v. 33, n. 19, p. 19-26, dez/fev. 1991.

Artigo submetido 10/02/11 e aceito 04/04/2011. 